\title{
EMERgênCIA E Desenvolvimento de GuanXuma (Sida rhombifolia), CAPIM-BRAgUIÁRIA (Brachiaria decumbens) E CANA-DE-AÇÚCAR (Saccharum spp.) INFLUENCIADOS POR SUBPRODUTOS DA DESTILAÇÃo Do ÁlCOOL ${ }^{1}$
}

\author{
Emergence and Growth of Arrowleaf Sida (Sida rhombifolia), Brachiaria Grass (Brachiaria \\ decumbens) and Sugarcane (Saccharum spp.) as Influenced by Alcohol by-Products
}

\author{
AZANIA, A.A.P.M. ${ }^{2}$, AZANIA, C.A.M. ${ }^{3}$, MARQUES, M.O. ${ }^{4}$ e PAVANI, M.C.M.D. ${ }^{5}$
}

\begin{abstract}
RESUMO - Este trabalho objetivou avaliar os efeitos da aplicação de óleo de fúsel, comparativamente a vinhaça e flegmaça, sobre o desenvolvimento e a composição química de plantas de guanxuma (Sida rhombifolia), capim-braquiária (Brachiaria decumbens) e canade-açúcar (variedade RB72454), cultivadas simultaneamente em casa de vegetação. As concentrações de 12,$5 ; 25,0 ; 50,0 ;$ e $100,0 \%$ (v/v) de cada subproduto e a testemunha (água) foram aplicadas (numa taxa equivalente a $150 \mathrm{~m}^{3} \mathrm{ha}^{-1}$ ) no solo dos vasos $(22 \mathrm{~L}$ ), contendo uma planta de cana-de-açúcar (13 cm de altura) e 100 sementes de cada planta daninha. $\mathrm{O}$ delineamento foi o inteiramente casualizado, com 13 tratamentos e 4 repetições, em esquema fatorial $3 \times 4$ (três tipos de resíduos e quatro concentrações), e uma testemunha adicional com água. O óleo de fúsel inibiu a emergência de Sida rhombifolia e Brachiaria decumbens e matou a cana-de-açúcar. A vinhaça e a flegmaça prejudicaram a emergência e o desenvolvimento de $B$. decumbens, bem como o de S. rhombifolia, mas não o da cana-deaçúcar.
\end{abstract}

Palavras-chave: óleo de fúsel, flegmaça, vinhaça e plantas daninhas.

\begin{abstract}
This research aimed to compare the effects of fusel oil application to those of vinasse and flegmass application on the growth and chemical composition of arrowleaf sida plants (Sida rhombifolia), brachiaria grass (Brachiaria decumbens) and sugarcane (Saccharum spp.), cultivated simultaneously under greenhouse conditions. Concentrations of 12.5,25.0,50.0 and $100.0 \%(\mathrm{v} / \mathrm{v})$ of each by-product and the check treatment (water) were applied (rate equivalent to $150 \mathrm{~m}^{3} \mathrm{ha}^{-1}$ ) to soil on $22 \mathrm{~L}$-pots, containing one sugar-cane plant (13 cm of height), and 100 seeds of each weed. The experimental design was completely randomized, with 13 treatments and 4 repetitions, in a $3 \times 4$ factorial scheme ( 3 by-products and 4 concentrations) and an additional check treatment with water. The fusel oil inhibited Sida rhombifolia and Brachiaria decumbens emergence with no emergence being verified for sugarcane. The vinasse and flegmass reduced B. decumbens emergence and growth and S. rhombifolia growth but did not affect sugarcane growth.
\end{abstract}

Key words: fusel oil, flegmass, vinasse and weeds.

1 Recebido para publicação em 4.1.2004 e na forma revisada em 10.9.2004.

Parte da dissertação de mestrado do primeiro autor.

2 Doutoranda em Produção Vegetal da FCAV/UNESP, bolsista CNPq, <padua@ fcav.unesp.br>; ${ }^{3}$ Doutorando em Produção Vegetal da FCAV/UNESP; ${ }^{4}$ Prof. Dr. do Departamento de Tecnologia da FCAV/UNESP; ${ }^{5}$ Prof ${ }^{\mathrm{a}}$. Dra ${ }^{\mathrm{a}}$. do Departamento de Biologia Aplicada à Agropecuária - FCAV/UNESP, Rod. Prof. Paulo D. Castellane, Km 5, 14870-000 Jaboticabal-SP. 


\section{INTRODUÇÃO}

Estudos sobre utilização racional de resíduos na agricultura são fundamentais para minimizar o problema de geração de resíduos pelas indústrias e pela população.

Nas destilarias encontram-se os maiores volumes de resíduos gerados pelas usinas. A vinhaça, também conhecida como vinhoto, é o principal resíduo da destilação do vinho; devido ao alto conteúdo de matéria orgânica e nutrientes, especialmente potássio, as usinas utilizam-na no processo de fertirrigação em parte de seus canaviais, em substituição total ou parcial à adubação mineral. Por isso, ela passou a ser considerada um subproduto do processo.

O óleo de fúsel está entre os principais subprodutos da destilação (retificação), sendo constituído por impurezas de alto grau de volatilização. Segundo Enriquez et al. (1989), a maioria dos componentes do óleo de fúsel são álcoois e ésteres. Entretanto, de acordo com Pérez et al. (2001), ele ainda não é devidamente aproveitado pelas usinas, pois é vendido para indústrias químicas por um baixo valor comercial.

A flegmaça é um resíduo obtido no processo de destilação (retificação) do álcool, sendo adicionada à vinhaça e aplicada no campo como substituto da adubação mineral.

Dentre os resíduos, a vinhaça é a mais pesquisada quanto à utilização nas culturas, em razão do seu alto conteúdo de nutrientes. Guanto à utilização em plantas daninhas, Balbo Jr. (1984) concluiu que a velocidade de emergência do fedegoso foi negativamente afetada. Christoffoleti \& Bacchi (1985) constataram que a mistura vinhaça + herbicidas controlou as plantas daninhas e que os herbicidas não tiveram sua eficácia prejudicada. $\mathrm{O}$ óleo de fúsel e a flegmaça, isoladamente, não possuem histórico de uso em áreas agrícolas.

Segundo Glória (1992), a utilização de resíduos no solo deve ser conduzida no sentido não só de eliminar a sua nocividade, mas também de tornar atraente o seu uso, quer como fonte de nutrientes às culturas, quer como condicionadores do solo. Nesses casos, é possível que os resíduos se tornem subprodutos, devendo passar a ter um valor de comércio.
Nesse contexto, este trabalho objetivou avaliar os efeitos da aplicação de concentrações crescentes de óleo de fúsel, comparativamente a vinhaça e flegmaça, no desenvolvimento e na composição química de plantas de guanxuma (Sida rhombifolia), capim-braquiária (Brachiaria decumbens) e cana-de-açúcar (variedade RB72454), cultivadas simultaneamente em casa de vegetação.

\section{MATERIAL E MÉTODOS}

O experimento foi conduzido em casa de vegetação, em vasos de $22 \mathrm{~L}$ de capacidade, preenchidos com terra peneirada, proveniente de um horizonte A moderado com textura argilosa, apresentando $\mathrm{pH}\left(\mathrm{CaCl}_{2}\right)=5,0$, matéria orgânica $=19 \mathrm{~g} \mathrm{dm}^{-3}, \mathrm{P}($ resina $)=$ $25 \mathrm{mg} \mathrm{m}^{-3}, \mathrm{~K}_{2} \mathrm{O}=1,5, \mathrm{Ca}=20, \mathrm{MgO}=11 \mathrm{e} \mathrm{H}+\mathrm{Al}$ $=28$, expressos em mmol $\mathrm{dm}^{-3}$.

Previamente, foram plantados minitoletes de cana-de-açúcar $(6 \mathrm{~cm})$, cultivar RB72454, contendo uma única gema, em copos de plástico $(500 \mathrm{~mL})$ preenchidos com terra vegetal. O transplantio para vasos de $22 \mathrm{~L}$ foi feito quando as plântulas atingiram altura de aproximadamente $13 \mathrm{~cm}$. Após 20 dias do transplante, foram semeadas em cada vaso 100 sementes de guanxuma e 100 de capimbraquiária. Os subprodutos foram aplicados, a $150 \mathrm{~m}^{3} \mathrm{ha}^{-1}$ (1,14 L por vaso), em préemergência das plantas daninhas e quando a cana-de-açúcar atingiu aproximadamente $31 \mathrm{~cm}$ de altura.

A vinhaça utilizada no experimento apresentou em sua composição química $\mathrm{pH}=$ 4,2 , matéria orgânica $=1,57 \%, \mathrm{~N}=0,38, \mathrm{P}_{2} \mathrm{O}_{5}$ $=0,045, \mathrm{~K}_{2} \mathrm{O}=2,17, \mathrm{CaO}=0,60, \mathrm{MgO}=0,50 \mathrm{e}$ $\mathrm{SO}_{4}=1,87$, expressos em kg m${ }^{-3}$, e $\mathrm{Cu}=1,0, \mathrm{Fe}$ $=51, \mathrm{Mn}=3,9$ e $\mathrm{Zn}=2,0$, expressos em $\mathrm{g} \mathrm{m}^{-3}$. A cromatografia do óleo de fúsel apresentou, em valores percentuais: etanol $(11,70)$, n-propanol $(0,83)$, i-butanol $(8,47), n$-butanol $(0,21)$, i-amílico $(28,66)$ e n-amílico $(0,12)$; na flegmaça apenas foi detectado etanol (0,043\%).

Após o transplante, a irrigação dos vasos foi feita com água, procurando atingir 80\% da capacidade de campo, diariamente, durante todo o período experimental. A adubação de plantio foi realizada apenas para a testemunha, empregando-se N, P e K de acordo com 
o resultado da análise de solo e com as recomendações de Espironelo (1992).

O delineamento experimental foi o inteiramente casualizado, com 13 tratamentos, resultantes da combinação dos subprodutos (flegmaça, óleo de fúsel e vinhaça) e concentrações $(12,5,25,0,50,0$ e 100,0\% (v/v)) e do tratamento testemunha, em quatro repetições. Tendo em vista os resultados obtidos, optou-se pelo esquema fatorial $2 \times 4$ (dois subprodutos e quatro concentrações), aplicandose análise de variância e o teste de Tukey a $5 \%$ de probabilidade.

Aos 10, 20 e 40 DAT (dias após tratamento), avaliou-se, na cana-de-açúcar, a altura da planta (medida do nível do solo até o dew lap); o teor de clorofila total das folhas (Unidades Relativas-UR), empregando-se clorofilômetro de campo Mod. Spad 502 Minolta; e o índice de fluorescência, avaliado na folha +3 , empregando-se fluorômetro portátil (modelo Hansatech). Ao final do experimento avaliaram-se: diâmetro de colmos, número de perfilhos, massa seca da parte aérea, composição química do material seco produzido (macro e micronutrientes, de acordo com metodologia de Sarruge \& Haag (1974).
Nas plantas daninhas foram determinadas a porcentagem de emergência $(10,20$ e 40 DAT), a massa seca da parte aérea (final do experimento) e a composição química do material seco produzido, também segundo a metodologia de Sarruge \& Haag (1974).

\section{RESULTADOS E DISCUSSÃO}

O óleo de fúsel inibiu a germinação de Sida rhombifolia e Brachiaria decumbens em todas as épocas avaliadas.

Para Sida rhombifolia, a vinhaça e a flegmaça não apresentaram interferência sobre a emergência aos 10 DAT; contudo, a partir dos 20 DAT a emergência da guanxuma foi menor para aplicação com vinhaça. Entretanto, com exceção da avaliação feita aos 20 DAT, o percentual de emergência para os tratamentos envolvendo os subprodutos foi próximo ao da testemunha - aos 40 DAT houve total recuperação (Tabela 1).

$O$ fato de os percentuais de emergência da guanxuma nas testemunhas terem sido próximos àqueles dos tratamentos com os subprodutos pode ser indicativo de que a vinhaça e a flegmaça não influenciaram negativamente a emergência desta planta.

Tabela 1 - Emergência de plântulas de Sida rhombifolia e Brachiaria decumbens aos 10, 20 e 40 dias após a aplicação dos tratamentos e massa seca produzida pelas plantas, no final do experimento. Efeitos da aplicação de vinhaça, flegmaça e suas concentrações. Resumo da análise estatística

\begin{tabular}{|c|c|c|c|c|c|c|c|c|}
\hline \multirow[b]{2}{*}{ Variável } & \multicolumn{3}{|c|}{ Emergência de S. rhombifolia $(\%)^{1 /}$} & \multicolumn{3}{|c|}{ Emergência de B. decumbens $(\%)^{1 /}$} & \multicolumn{2}{|c|}{ Massa seca $(\mathrm{g})$} \\
\hline & 10 DAT & 20 DAT & 40 DAT & 10 DAT & 20 DAT & $40 \mathrm{DAT}$ & Sida rhombifolia & $\begin{array}{l}\text { Brachiaria } \\
\text { decumbens }\end{array}$ \\
\hline \multicolumn{9}{|l|}{ Subprodutos (A) } \\
\hline Vinhaça & 18,18 & $19,52 \mathrm{~b}$ & $33,73 \mathrm{~b}$ & 45,29 & $45,41 \mathrm{~b}$ & 48,89 & 0,35 & 4,97 \\
\hline Flegmaça & 17,80 & $22,62 \mathrm{a}$ & $38,15 \mathrm{a}$ & 46,34 & $48,66 \mathrm{a}$ & 48,59 & 0,27 & 4,92 \\
\hline \multicolumn{9}{|l|}{ Concentr. (B) - (v/v) } \\
\hline 12,5 & 17,59 & 22,93 & 36,55 & $46,88 \mathrm{ab}$ & $47,30 \mathrm{ab}$ & 48,20 & 0,32 & $7,24 \mathrm{a}$ \\
\hline 25,0 & 17,27 & 21,53 & 38,41 & $47,38 \mathrm{a}$ & $48,62 \mathrm{ab}$ & 50,61 & 0,21 & $3,33 \mathrm{~b}$ \\
\hline 50,0 & 19,52 & 19,85 & 35,50 & $47,62 \mathrm{a}$ & $49,65 \mathrm{a}$ & 50,47 & 0,38 & $4,98 \mathrm{ab}$ \\
\hline 100,0 & 17,59 & 19,96 & 33,30 & $41,39 \mathrm{~b}$ & $42,58 \mathrm{~b}$ & 45,66 & 0,32 & $4,23 \mathrm{ab}$ \\
\hline \multirow[t]{2}{*}{ Testemunha } & 15,75 & 21,00 & 35,25 & 61,00 & 62,75 & 66,75 & 0,60 & 9,13 \\
\hline & \multicolumn{8}{|c|}{ Teste F } \\
\hline Subprodutos (A) & $0,04 \mathrm{NS}$ & $4,44 *$ & $4,39 *$ & $0,50 \mathrm{NS}$ & $4,12 *$ & $0,01 \mathrm{NS}$ & $1,68 \mathrm{NS}$ & $0,00 \mathrm{NS}$ \\
\hline Concentraçōes(B) & $0,30 \mathrm{NS}$ & $0,99 \mathrm{NS}$ & $1,02 \mathrm{NS}$ & $4,01 *$ & $3,82 *$ & $0,87 \mathrm{NS}$ & $1,27 \mathrm{NS}$ & $3,34 *$ \\
\hline $\mathrm{A} \times \mathrm{B}$ & $1,64 \mathrm{NS}$ & $1,86 \mathrm{NS}$ & $1,05 \mathrm{NS}$ & $4,27 *$ & $3,68 *$ & $0,73 \mathrm{NS}$ & $1,14 \mathrm{NS}$ & $0,98 \mathrm{NS}$ \\
\hline Testemunha $\mathrm{x}$ fatorial & $2,84 \mathrm{NS}$ & $8,41 * *$ & $0,05 \mathrm{NS}$ & $7,05 *$ & $5,79 *$ & $2,97 \mathrm{NS}$ & $9,41 * *$ & $9,33 * *$ \\
\hline $\mathrm{CV}(\%)$ & 28,72 & 19,13 & 16,56 & 9,02 & 9,49 & 14,28 & 52,77 & 47,7 \\
\hline
\end{tabular}

1/ Dados transformados em Arc sen (raiz $((\mathrm{x}+0,5) / 100))$; DAT - dias após tratamento; (v/v) volume/volume; letras iguais não diferem estatisticamente; NS - não-significativo; * significativo a $5 \%$ de probabilidade; ** significativo a $1 \%$ de probabilidade. 
Embora a vinhaça e a flegmaça não tenham afetado negativamente a emergência de Sida rhombifolia, o desenvolvimento de suas plântulas, observado pela massa seca do material, foi menor para ambos os subprodutos, quando comparado com a testemunha (Tabela 1). Possivelmente, a vinhaça e a flegmaça tenham proporcionado condições desfavoráveis ao desenvolvimento dessas plântulas no solo.

O desbalanceamento nutricional da vinhaça (Centurión \& Derísio, 1993) pode ter colaborado com o pouco desenvolvimento das plantas, pois Kissmann \& Groth (2000) comentaram que Sida rhombifolia desenvolve-se melhor em solos adubados e corrigidos, podendo atingir até $1,50 \mathrm{~m}$.

Em razão do pouco desenvolvimento das plântulas de Sida rhombifolia, a quantidade de material seco coletado aos 40 DAT foi insuficiente para analisar a composição química das plantas de guanxuma, as quais, conseqüentemente, não puderam ser analisadas estatisticamente.

Para Brachiaria decumbens, os tratamentos com vinhaça reduziram a emergência das plântulas, principalmente aos 20 DAT, com total recuperação aos 40 DAT. As maiores diferenças entre os subprodutos e suas concentrações sobre a emergência das plântulas também ocorreram até os 20 DAT (Tabela 1).

As sementes de capim-braquiária submetidas ao tratamento com vinhaça ou flegmaça apresentaram menor emergência que aquelas da testemunha, até os 20 DAT (Tabela 1). O fato de a emergência nas testemunhas ter sido maior que nos tratamentos com os subprodutos indica que a vinhaça e a flegmaça interferiram negativamente na emergência das plântulas, até próximo dos 40 DAT, quando estas apresentaram total recuperação.

Assim como para Sida rhombifolia, as plântulas de Brachiaria decumbens apresentaram-se com o desenvolvimento prejudicado, provavelmente devido à aplicação dos subprodutos. Ocorre que o desenvolvimento das plântulas do capim-braquiária na testemunha apresentou maior massa seca que aquelas dos tratamentos com subprodutos, aos 40 DAT (Tabela 1). Segundo Kissmann (1997), o capim-braquiária desenvolve-se rapidamente após a germinação, em condição de umidade e calor. No entanto, esse desenvolvimento somente ocorreu nos tratamentos testemunhas, indicando que os tratamentos com vinhaça e flegmaça podem ter prejudicado o desenvolvimento das plantas de Brachiaria decumbens.

Observa-se, na Tabela 2, que a vinhaça na maior concentração foi a principal responsável pela redução da emergência das plântulas. Possivelmente a vinhaça tenha proporcionado uma maior concentração de sais (potássio, magnésio, cálcio) e também elevação do pH no solo (Leal et al., 1983), colaborando com a redução da emergência das plantas. Além da variação do $\mathrm{pH}$, a concentração de sais no solo pode ter formado um maior potencial osmótico em torno da semente e prejudicado a germinação.

Tabela 2 - Desdobramento da interação entre os subprodutos vinhaça e flegmaça e suas concentrações de aplicação sobre o estado nutricional (40 DAT) e a emergência das plantas de Brachiaria decumbens

\begin{tabular}{|c|c|c|c|c|c|c|c|}
\hline \multirow{2}{*}{ Variável } & \multirow{2}{*}{$\begin{array}{l}\text { Conc. } \\
(\mathrm{v} / \mathrm{v})\end{array}$} & \multicolumn{4}{|c|}{ Subproduto } & \multirow{2}{*}{\multicolumn{2}{|c|}{$\mathrm{F}$}} \\
\hline & & \multicolumn{2}{|c|}{ Vinhaça } & \multicolumn{2}{|c|}{ Flegmaça } & & \\
\hline \multirow{5}{*}{$\begin{array}{c}\text { Emergência } \\
\text { (10 DAT) }\end{array}$} & 12,5 & 49,33 & A A & 44,43 & $\mathrm{~A} \mathrm{~A}$ & 2,73 & NS \\
\hline & 25,0 & 47,02 & $\mathrm{~A} \mathrm{a}$ & 47,74 & $\mathrm{~A} \mathrm{a}$ & 0,06 & NS \\
\hline & 50,0 & 48,21 & $\mathrm{Aa}$ & 47,04 & $\mathrm{Aa}$ & 0,16 & NS \\
\hline & 100,0 & 36,62 & $\mathrm{~B} \mathrm{~b}$ & 46,15 & $\mathrm{Aa}$ & 10,35 & $* *$ \\
\hline & $\mathrm{F}$ & 7,82 & $* *$ & 0,47 & NS & & \\
\hline \multirow{5}{*}{$\begin{array}{c}\text { Emergência } \\
(20 \text { DAT) }\end{array}$} & 12,5 & 48,30 & $\mathrm{AA}$ & 46,29 & $\mathrm{AA}$ & 0,40 & NS \\
\hline & 25,0 & 47,59 & $\mathrm{Aa}$ & 49,65 & $\mathrm{Aa}$ & 0,42 & NS \\
\hline & 50,0 & 49,22 & $\mathrm{Aa}$ & 50,08 & $\mathrm{Aa}$ & 0,07 & NS \\
\hline & 100,0 & 36,53 & $\mathrm{Bb}$ & 48,62 & $\mathrm{Aa}$ & 14,29 & $* *$ \\
\hline & $\mathrm{F}$ & 6,94 & $* *$ & 0,56 & NS & & \\
\hline \multirow{5}{*}{$\begin{array}{l}\mathrm{K}-\mathrm{g} \mathrm{kg}^{-1} \\
\left(40 \mathrm{D}^{\prime} \mathrm{AT}\right)\end{array}$} & 12,5 & 28,10 & $\mathrm{AA}$ & 24,13 & Bв & 13,03 & $* *$ \\
\hline & 25,0 & 29,18 & $\mathrm{Aa}$ & 28,38 & $\mathrm{Aa}$ & 0,53 & NS \\
\hline & 50,0 & 28,03 & $\mathrm{Aa}$ & 28,68 & Aa & 0,35 & NS \\
\hline & 100,0 & 28,65 & $\mathrm{Aa}$ & 26,53 & $\mathrm{Aab}$ & 3,72 & NS \\
\hline & $\mathrm{F}$ & 0,47 & NS & 7,24 & $* *$ & & \\
\hline \multirow{5}{*}{$\begin{array}{l}S-g_{k g}^{-1} \\
(40 \text { DAT) }\end{array}$} & 12,5 & 1,85 & $\mathrm{AA}$ & 1,38 & BB & 4,98 & $*$ \\
\hline & 25,0 & 2,00 & $\mathrm{Aa}$ & 2,28 & $\mathrm{Aa}$ & 1,67 & NS \\
\hline & 50,0 & 1,45 & $\mathrm{Aa}$ & 1,58 & $\mathrm{Ab}$ & 0,34 & NS \\
\hline & 100,0 & 2,03 & $\mathrm{Aa}$ & 1,5 & $\mathrm{Bb}$ & 4,98 & $*$ \\
\hline & $F$ & 3,11 & NS & 6,98 & $* *$ & & \\
\hline
\end{tabular}

(v/v) volume/volume; DAT - dias após tratamento; médias seguidas de letras iguais não diferem estatisticamente; NS - não-significativo; * significativo a $5 \%$ de probabilidade; ** significativo a $1 \%$ de probabilidade. Letras maiúsculas - comparação na horizontal. Letras minúsculas - comparação na vertical. 
Quanto ao conteúdo nutricional realizado aos 40 DAT, com exceção do enxofre, verificouse que as plantas de Brachiaria decumbens retiram mais nutrientes do solo do que a canade-açúcar (dados não apresentados). Segundo Blanco et al. (1979, 1981), as plantas daninhas são grandes extratoras de nutrientes do solo.

O conteúdo de nitrogênio das plantas de Brachiaria decumbens não diferiu entre os tratamentos com subprodutos ou testemunha (Tabela 3). De acordo com Bianco et al. (2000), o nitrogênio é o segundo macronutriente requerido em maior quantidade pelas plantas de capim-braquiária.

No que se refere ao fósforo, o maior conteúdo foi observado devido à aplicação de vinhaça, provavelmente em virtude da maior concentração do nutriente em sua composição química (Tabela 3). Na testemunha, mesmo recebendo adubação mineral, o fósforo teve tendência de redução, provavelmente devido à baixa mobilidade no solo. Segundo Prevedello \& Reissmann (2002), as plantas aproveitam o fósforo do solo de formas diferentes - plantas com crescimento rápido e raízes pouco desenvolvidas aproveitam menos este elemento.

O conteúdo de potássio decorrente da aplicação de vinhaça também foi maior nas folhas de Brachiaria decumbens (Tabela 3). Entretanto, esse comportamento deve-se, provavelmente, ao fato de a vinhaça ter em sua composição uma maior quantidade de potássio (Penatti et al., 1988), além de ser o elemento mais acumulado na seqüência de acúmulo de nutrientes em plantas de capim-braquiária (Bianco et al., 2000). O desdobramento da interação subprodutos x doses, na Tabela 2 , mostra que a flegmaça diferiu da vinhaça, com redução do conteúdo de potássio na concentração 12,5\%, indicando a pouca quantidade de potássio existente em sua composição.

Nas plantas de Brachiaria decumbens, os teores de cálcio, ferro, manganês, enxofre e zinco não foram influenciados pela vinhaça e flegmaça; o conteúdo de cobre $\left(3,63 \mathrm{mg} \mathrm{kg}^{-1}\right)$ foi maior com a aplicação de vinhaça, pelo fato de esta apresentar este elemento em sua composição; o acúmulo de magnésio foi maior no tratamento com flegmaça, quando comparada à vinhaça ou testemunha (Tabela 3).

O óleo de fúsel, em 24 horas após aplicação, causou a murcha das plantas de canade-açúcar, num processo irreversível e progressivo de secagem das folhas e dos ramos. Nesse sentido, o óleo de fúsel apresentou um potencial dessecante sobre as plantas, devendo ser melhor estudado em outros trabalhos. Devido à morte das plantas de cana-de-açúcar nos tratamentos com o óleo de fúsel, não foi possivel fazer a análise nutricional nas folhas.

Tabela 3 - Estado nutricional das plantas de Brachiaria decumbens aos 40 dias após a aplicação dos tratamentos. Efeitos da aplicação de vinhaça, flegmaça e suas concentrações. Resumo da análise estatística

\begin{tabular}{|c|c|c|c|c|c|c|c|c|c|c|}
\hline \multirow{2}{*}{ Variável } & $\mathrm{N}$ & $\mathrm{P}$ & $\mathrm{K}$ & $\mathrm{Ca}$ & $\mathrm{Mg}$ & $\mathrm{S}$ & $\mathrm{Cu}$ & $\mathrm{Fe}$ & $\mathrm{Mn}$ & $\mathrm{Zn}$ \\
\hline & \multicolumn{6}{|c|}{$\left(\mathrm{g} \mathrm{kg}^{-1}\right)$} & \multicolumn{4}{|c|}{$\left(\mathrm{mg} \mathrm{kg}^{-1}\right)$} \\
\hline \multicolumn{11}{|l|}{ Subprodutos (A) } \\
\hline Vinhaça & 9,34 & $3,45 \mathrm{a}$ & $28,49 \mathrm{a}$ & 2,93 & $4,55 \mathrm{~b}$ & 1,83 & $3,63 \mathrm{a}$ & 145,00 & 39,00 & 16,88 \\
\hline Flegmaça & 9,09 & $3,04 \mathrm{~b}$ & $26,93 \mathrm{~b}$ & 3,06 & $5,94 \mathrm{a}$ & 1,69 & $3,00 \mathrm{~b}$ & 176,44 & 37,31 & 15,19 \\
\hline \multicolumn{11}{|l|}{ Concentr. (B) - (v/v) } \\
\hline 12,5 & 9,22 & 2,99 & $26,11 \mathrm{~b}$ & 3,04 & 5,51 & $1,61 \mathrm{~b}$ & 3,13 & 168,00 & 32,63 & 15,38 \\
\hline 25,0 & 8,12 & 3,48 & $28,78 \mathrm{a}$ & 3,00 & 4,73 & $2,14 \mathrm{a}$ & 3,50 & 183,38 & 40,25 & 16,75 \\
\hline 50,0 & 9,65 & 2,96 & $28,35 \mathrm{a}$ & 2,98 & 5,45 & $1,51 \mathrm{~b}$ & 3,25 & 117,50 & 37,00 & 16,00 \\
\hline 100,0 & 9,89 & 3,55 & $27,59 \mathrm{ab}$ & 2,96 & 5,29 & $1,79 \mathrm{ab}$ & 3,38 & 174,00 & 42,75 & 16,00 \\
\hline Testemunha & 9,28 & 2,80 & 26,98 & 3,50 & 5,78 & 1,58 & 2,00 & 111,00 & 46,00 & 16,50 \\
\hline & \multicolumn{10}{|c|}{ Teste F } \\
\hline Subprodutos (A) & $0,24 \mathrm{NS}$ & $5,33 *$ & $8,05 * *$ & $1,79 \mathrm{NS}$ & $7,22 *$ & $1,67 \mathrm{NS}$ & $4,33 *$ & 1,84 NS & $0,25 \mathrm{NS}$ & $3,60 \mathrm{NS}$ \\
\hline Concentrações (B) & $2,34 \mathrm{NS}$ & $3,05 \mathrm{NS}$ & $4,52 *$ & $0,10 \mathrm{NS}$ & $0,48 \mathrm{NS}$ & $6,66 * *$ & $0,29 \mathrm{NS}$ & $1,62 \mathrm{NS}$ & $1,65 \mathrm{NS}$ & $0,40 \mathrm{NS}$ \\
\hline $\mathrm{A} \times \mathrm{B}$ & $0,90 \mathrm{NS}$ & $0,60 \mathrm{NS}$ & $3,19 *$ & $1,32 \mathrm{NS}$ & $1,66 \mathrm{NS}$ & $3,43 * *$ & $0,75 \mathrm{NS}$ & $0,41 \mathrm{NS}$ & $0,30 \mathrm{NS}$ & $0,36 \mathrm{NS}$ \\
\hline Testemunha $\mathrm{x}$ fatorial & $0,01 \mathrm{NS}$ & $2,74 \mathrm{NS}$ & $0,78 \mathrm{NS}$ & $10,77 * *$ & $0,47 \mathrm{NS}$ & $1,38 \mathrm{NS}$ & $8,48 * *$ & $2,05 \mathrm{NS}$ & $2,36 \mathrm{NS}$ & $0,12 \mathrm{NS}$ \\
\hline $\mathrm{CV}(\%)$ & 15,73 & 15,83 & 5,64 & 9,54 & 27,55 & 17,29 & 26,84 & 42,20 & 24,65 & 15,64 \\
\hline
\end{tabular}

(v/v) volume/volume; NS (não-significativo); * significativo a $5 \%$ de probabilidade; ** significativo a $1 \%$ de probabilidade. 
Nos tratamentos com vinhaça e flegmaça, as plantas de cana-de-açúcar não tiveram o desenvolvimento prejudicado; aos 40 DAT apresentaram-se com excelente estado de vigor e com acúmulo de nutrientes dentro dos padrões normais, segundo as referências encontradas na literatura.

No entanto, considerando o período de 40 DAT e as condições do experimento, o óleo de fúsel inibiu a emergência das plântulas de Sida rhombifolia e Brachiaria decumbens e levou as plantas de cana-de-açúcar à morte. A vinhaça e a flegmaça prejudicaram a emergência e o desenvolvimento das plantas de Brachiaria decumbens e o desenvolvimento das plantas de Sida rhombifolia, até os 40 DAT.

\section{LITERATURA CITADA}

BALBO JR., L. Estudos preliminares dos efeitos da vinhaça sobre a emergência e desenvolvimento inicial de plantas daninhas. I - Fedegoso (Cassia tora L.). $41 \mathrm{f}$. Jaboticabal, Universidade Estadual Paulista, 1984.

Monografia (Trabalho de graduação em Agronomia).

BIANCO, S. et al. Produção de matéria seca e marcha de absorção de macronutrientes por plantas de capimbraquiária. In: CONGRESSO BRASILEIRO DA CIÊNCIA DAS PLANTAS DANINHAS, 22., 2000, Foz do Iguaçu. Resumos... Londrina: Sociedade Brasileira da Ciência das Plantas Daninhas, 2000. p. 61.

BLANCO, H. G.; OLIVEIRA, D. A.; ARAÚJO, J. B. M. Competição entre plantas daninhas e a cultura da cana-deaçúcar. I. Período crítico de competição produzido por uma comunidade natural de dicotiledôneas em cultura de ano. Biológico, v. 45, n. 7/8, p. 131-140, 1979.

BLANCO, H. G.; OLIVEIRA, D. A.; COLETI, J. T. Competição entre plantas daninhas e a cultura da cana-deaçúcar. II. Período de competição produzido por uma comunidade natural de mato, com predomínio de gramíneas, em cultura de ano. III-Influência da competição na nutrição da cana-de-açúcar. Biológico, v. 47, n. 3, p. 77-88, 1981.

CENTURIÓN, R. E. B.; DERÍSIO, J. C. Evolução do controle da poluição das indústrias sucro-alcooleiras no Estado de São Paulo. Álcool \& Açúcar, v. 12, n. 68, p. 24-35, 1993.
CHRISTOFFOLETI, P. J.; BACCHI, O. O. S. Efeito da aplicação de vinhaça sobre a população e controle químico de plantas daninhas na cultura da cana-de-açúcar (Saccharum spp.). Planta Daninha, v. 8, n. 1/2, p. 60-70, 1985.

ENRIQUEZ, M.; SANZ, J.; CANO, M. Preliminary analysis by gas chromatography and mass spectrometry (GC/MS) of fusel oil originating from three Cuban sugar factories. R. ICIDCA derivados cana azucar, v. 1, n. 23, p. 34-39, 1989.

ESPIRONELO, A. Cana-de-açúcar. In: RAIJ, B. van et al. (Eds.) Recomendações de adubação e calagem para o Estado de São Paulo. Campinas: Instituto Agronômico, 1992. 107 p. (Boletim Técnico, 100).

GLORIA, N. A. Uso agronômico de resíduos. In: REUNIÃO BRASILEIRA DE FERTILIDADE DO SOLO E NUTRIÇÃO DE PLANTAS, 20., 1992, Piracicaba. Anais... Piracicaba: ESALQ/USP, 1992. p. 1-17.

KISSMANN, K. G. Plantas infestantes e nocivas. 2.ed. São Paulo: BASF Brasileira, 1997. v. 1. p. 393-401.

KISSMANN, K. G.; GROTH, D. Plantas infestantes e nocivas. 2.ed. São Paulo: BASF Brasileira, 2000. v. 3. p. $159-162$.

LEAL, J. R. et al. Potencial redox e pH: variações em um solo tratado com vinhaça. R. Bras. Ci. Solo, v. 7, p. 257261, 1983.

PENATTI, C. P. et al. Recomendações de adubação para a cultura de cana-de-açúcar. In: SEMINÁRIO DE TECNOLOGIA AGRONÔMICA, 1988, Piracicaba. Anais... Piracicaba: ESALQ/USP, 1988. p. 103-114.

PÉREZ, E. R.; CARDOSO, D. R.; FRANCO, D. W. Análise dos álcoois, ésteres e compostos carbonílicos em amostras de óleo fúsel. Química Nova, v. 24, n. 1, p. 10-12, 2001.

PREVEDELLO, B. M. S.; REISSMANN, C. B. Nutrição mineral das plantas. In: WACHOWICZ, C. M.; CARVALHO, R. I. N. (Orgs.) Fisiologia Vegetal: produção e pós-colheita. Curitiba, Champagnat, 2002. p. 115-133.

SARRUGE, J. R.; HAAG, H. P. Análises químicas em plantas. Piracicaba: Escola Superior de Agricultura "Luiz de Queiroz", 1974. 56 p. Apostila. 